\title{
Prevalence of Pain on Admission by Level of Cognitive Impairment in Nursing Homes
}

This article was published in the following Dove Press journal:

Journal of Pain Research

\author{
Catherine E Dube (D) \\ Reynolds A Morrison \\ Deborah S Mack (D) \\ Bill M Jesdale \\ Anthony P Nunes \\ Shao-Hsien Liu \\ Kate L Lapane $\mathbb{D}$
}

Division of Epidemiology, Department of Population and Quantitative Health Sciences, University of Massachusetts Medical School, Worcester, MA, USA
Correspondence: Kate L Lapane

Division of Epidemiology, Department of Population and Quantitative Health Sciences, University of Massachusetts Medical School, 398 Plantation Street, Worcester, MA 01655 , USA

Tel + I 508-856-8965

$\mathrm{Fax}+$ I 508-856-8993

Email kate.lapane@umassmed.edu
Purpose: To provide contemporary estimates of pain by level of cognitive impairment among US nursing home residents without cancer.

Methods: Newly admitted US nursing home residents without cancer assessed with the Minimum Data Set 3.0 at admission (2010-2016) were eligible $(n=8,613,080)$. The Cognitive Function Scale was used to categorize level of cognitive impairment. Self-report or staff-assessed pain was used based on a 5-day look-back period. Estimates of adjusted prevalence ratios (aPR) were derived from modified Poisson models.

Results: Documented prevalence of pain decreased with increased levels of cognitive impairment in those who self-reported pain $(68.9 \%$ no/mild, $32.9 \%$ severe $)$ and those with staff-assessed pain (50.6\% no/mild, 37.2\% severe staff-assessed pain). Relative to residents with no/mild cognitive impairment, pharmacologic pain management was less prevalent in those with severe cognitive impairment (self-reported: $51.3 \%$ severe vs $76.9 \%$ in those with no/mild; staff assessed: $52.0 \%$ severe vs $67.7 \%$ no/mild).

Conclusion: Pain was less frequently documented in those with severe cognitive impairment relative to those with no/mild impairments. Failure to identify pain may result in untreated or undertreated pain. Interventions to improve evaluation of pain in nursing home residents with cognitive impairment are needed.

Keywords: pain, nursing homes, cognitive impairment, dementia

\section{Plain Language Summary}

Pain is commonly experienced by older adults. Previously, assessment tools systematically used in US nursing homes were based on staff observations, rather than resident self-report. In the US, including the opportunity for residents to self-report pain as part of the geriatric assessment conducted in virtually all nursing homes may have improved recognition of pain. We provide contemporary estimates of pain prevalence in residents without cancer across US nursing homes. We believed that cognitively impaired nursing home residents experience pain at a similar frequency as residents who are cognitively intact and that most of the difference in reported pain and treatment of pain between these groups is due to flaws in identification and assessment. We found that pain prevalence and treatments to manage pain among newly admitted nursing home residents without cancer was lower in those with the most severe level of cognitive impairment relative to residents with no/mild cognitive deficits. This study highlights ongoing challenges of pain assessment and treatment among nursing home residents with severe cognitive impairment.

\section{Introduction}

Nursing home residents commonly experience pain. ${ }^{1,2}$ For those with cancer, the sources of pain are often multifactorial and include the disease itself, the treatments 
for the disease, and comorbid conditions related to pain ${ }^{3}$ and there are different mechanisms generating pain (eg, tissue damage versus nerve injury). Less is known about nonmalignant cancer pain in nursing home residents. Typical causes include symptoms related to medical conditions (musculoskeletal, gastrointestinal, neurological, cardiac), genitourinary infections, and physical injuries (recent or previous). ${ }^{4-6}$

While assessing pain in nursing home residents can be challenging due to multiple sources of pain, ${ }^{7}$ cognitive impairment is a key barrier to pain assessment in this setting. ${ }^{8}$ Nearly two-thirds of nursing home residents have cognitive impairment or dementia. ${ }^{9}$ Severe cognitive impairment is characterized by disturbance of higher cortical functions that interfere with understanding, assessment, and accurate recall and can result in impaired memory, judgement, abstract thinking, learning, calculation, and language skills, ${ }^{10,11}$ as well as disorientation in time and time distortion. ${ }^{12,13}$ These factors make selfreport of pain unreliable in those with severe cognitive impairment. In these residents, recognition of pain may depend on staff awareness of behaviors indicative of pain (eg, facial expressions, utterances). Although pain is prevalent in nursing home residents with cognitive impairment and dementia, ${ }^{14}$ less is known about how pain prevalence varies across levels of cognitive impairment.

This paper provides contemporary national estimates of pain by level of cognitive impairment among nursing home residents without cancer. While more research is available in nursing home residents with cancer, less is known about non-malignant pain in this setting. Based on previous work on residents with cancer, ${ }^{15}$ we hypothesized that, despite enhancements to the geriatric assessment process in nursing homes in the United States, the prevalence of documented pain and pain treatment would be lower among those with cognitive impairment relative to those with minimal cognitive deficits.

\section{Methods}

We conducted a descriptive cross-sectional study. We used data from the national nursing home Minimum Data Set (MDS 3.0) data. ${ }^{16,17}$ The MDS is a comprehensive geriatric assessment completed on all nursing home residents in Medicare/Medicaid-certified US nursing homes. Approximately $96-98 \%$ of US nursing homes are Medicare/Medicaid certified. Coordinate by a registered nurse with input from various members of the interdisciplinary healthcare team, the improved MDS $3.0^{18}$ incorporates the "resident voice."18-20 Our sample included all newly admitted nursing home residents from October 2010 to 2016; we selected the first admission. Residents in a comatose state were excluded. We included only residents $\geq 50$ years of age because people of younger age living in nursing homes are quite different from older nursing home residents. We included residents with no evidence of cancer.

\section{Cognitive Impairment}

We used the Cognitive Function Scale which includes the Brief Interview of Mental Status (BIMS) ${ }^{21,22}$ and the Cognitive Performance Scale (CPS). ${ }^{23,24}$ Staff completing the MDS 3.0 first determine if it is appropriate to conduct the BIMS based on characteristics of the resident being assessed. If a resident is rarely or never understood verbally or in writing, the BIMS is skipped. The MDS Manual $^{17}$ states that the interview should be conducted in a private setting that the interviewer must make sure the resident can hear the questions with usual communication devices (eg, hearing aids) or techniques applied, and that every effort should be made to engage an interpreter if one is needed to conduct the BIMS with non-English speakers. BIMS scores were classified as: 1) cognitively intact (score 13-15), 2) moderate cognitive impairment (score 8-12), and 3) severe cognitive impairment (score 0-7). BIMS has high sensitivity and specificity when compared to the Modified Mini-Mental State Examination (MMSE). ${ }^{21}$ For those who are rarely/never understood, BIMS is skipped and instead, standard items from the MDS are used to calculate the CPS, ${ }^{23,24}$ which compares favorably to the MMSE.20 CPS scores were classified as: 1) cognitively intact or mild cognitive impairment (CPS score 0-2), 2) moderate cognitive impairment (CPS score 3-4), and 3) severe cognitive impairment (CPS score 5-6).

\section{Pain}

The MDS 3.0 requires that staff must first attempt to assess pain based on resident self-report. If a resident is comatose, the attempt to assess pain based on resident selfreport is skipped. If a resident cannot communicate by talking, gestures, or written communication, the selfreport assessment is skipped. If staff do not speak the language of the resident, attempts are made to have an interpreter present. The MDS does not document if an interpreter assisted. If attempts to obtain self-reported pain fail, the staff document pain relying on their observations of the resident and review of medical records. The 
lookback period for all questions regarding pain was five days preceding the assessment. This assessment period was consistent whether pain was successfully assessed via self-report or if staff inferred pain based on their observations. The presence of pain was defined as any pain detected in the preceding five days (Yes/No). Residents elected to report their pain using a numerical pain rating scale or a verbal descriptor scale. Pain was further characterized relying on measures of frequency (rarely, occasionally, frequently, almost constantly), and intensity using a numeric pain rating scale (1-10 scale for pain intensity) or a verbal descriptor scale (mild, moderate, severe, very severe/horrible). We categorized residents by combining these responses (verbal descriptor scale "mild" or numeric rating scale 1 to 4 , verbal descriptor scale "moderate" or numeric rating scale 5 to 7 , verbal descriptor scale "severe" or numeric rating scale 8 to 9 , and verbal descriptor scale "very severe, horrible" or numeric rating scale 10).

For staff-assessed pain, the MDS manual outlines a consistent approach to pain observation because such an approach is thought to improve the accuracy of pain assessment for residents unable to complete the selfreported pain section. The MDS manual advises staff to observe residents for indicators of pain during activities bathing, transferring, dressing, walking, and eating as pain is likely to occur in these contexts. Staff conducting the assessment carefully monitor, track, and document any possible signs and symptoms of pain including vocal complaints, non-verbal, facial expressions of pain, and protective body movements. Each are indicated separately on the MDS. When completing this section, the nursing home healthcare professional reviews the medical record for documentation of each pain behavior in the 5-day lookback period. If documented, the information is confirmed with the direct care staff on all shits who work closely with the resident during ADLs. The healthcare professional also interviews direct care staff most involved in the resident's care to learn if any pain behaviors have been observed. In addition, the healthcare provider completing the MDS also observes the resident during ADLs and notes if any of the pain behaviors (vocal complaints, non-verbal, facial expressions of pain, or protective body movements) occur. For this paper, we categorized residents with any of these pain behaviors as being in pain. For staff-assessed pain, frequency was recorded as 1-2 days, 3-4 days, or daily.

\section{Pain Management}

The MDS 3.0 includes three items documenting pharmacological and non-pharmacological pain management strategies used in the five days preceding the assessment or, for residents in the nursing home for less than five days, the span of time from entry to the assessment. This includes 1) scheduled pain medications received, 2) pro re nata (PRN) medications received or offered and declined, 3) nonpharmacologic approaches for pain. Response sets for each item were binary. The MDS 3.0 does not detail specific medications or types of non-pharmacologic management of pain. Using these three binary variables, we created one four-level hierarchical variable with the following categories: 1) any scheduled medications (with or without PRN medications or non-pharmacological interventions), 2) PRN medications (with or without nonpharmacological interventions), 3) non-pharmacological interventions in the absence of pharmacological interventions (scheduled or PRN), or 4) no interventions for pain.

\section{Covariates}

Factors thought to impact cognitive impairment and/or pain included sociodemographic factors (eg, age in years (50-64, 65-74, 75-84, $\geq 85)$, sex, race/ethnicity, marital status), activities of daily living (ADL) dependency status (independent-limited assistance required, extensive assistance required, or dependent-total dependence), ${ }^{25}$ and hospice use. We also considered ability to make self understood either verbally or through non-verbal communication, ability to understand others with devices such as hearing aids if need be, and rejects care ("Did the resident reject evaluation or care that is necessary to achieve the resident's goal for achieving health and well-being?"). We also considered active clinical diagnoses of dementia/ Alzheimer's disease, depression, and anxiety, determined by documentation (eg, progress notes, discharge summaries, transfer notes, etc.) by a clinician (as permitted by state law) within 60 days preceding the assessment.

We included potentially painful conditions such as heart failure, coronary artery disease (including angina, myocardial infarction, and atherosclerotic heart disease), venous thromboembolism (including deep vein thrombosis, pulmonary embolism, and pulmonary thrombosis embolism), peripheral vascular/arterial disease, inflammatory bowel disease or ulcerative colitis, skin conditions (surgical wounds, 2ndand 3rd-degree burns, open lesions, pressure ulcers, foot problems such as infection of the foot, diabetic foot ulcer, 
or other open lesions on the foot), arthritis, osteoporosis, fractures, and urinary tract infections. ${ }^{15}$

\section{Analytic Approach}

We first described the sample overall and by level of cognitive impairment. Crude and adjusted prevalence ratios (aPR) were estimated for the association between level of cognitive impairment and any pain. We used modified robust Poisson models, ${ }^{26}$ which allowed us to directly estimate the prevalence ratios desired while adjusting for resident clustering within nursing home facilities. We evaluated associations separately for self-reported and staff-reported pain because we believed that the misclassification of pain may have been more pronounced in nursing home residents with staffassessed pain.

\section{Results}

Most residents were women (62.5\%), with $34.0 \%$ aged $\geq 85$ years. The majority were non-Hispanic White $(82.3 \%)$, $10.5 \%$ were non-Hispanic Black, and $4.8 \%$ were Hispanic or Latino. One in three were married (33.9\%) and one in five was dependent in activities of daily living. Nineteen percent had severe cognitive impairment and $22.9 \%$ had moderate cognitive impairment. Among residents with severe cognitive impairment, $14.3 \%$ rejected care and $33.9 \%$ were dependent in activities of daily living (Table 1). Of those with moderate cognitive impairment, $23.3 \%$ were dependent in activities of daily living. Nine out of ten residents with moderate cognitive impairment were assessed as able to make themselves understood (90.7\%) and understand others (90.4\%). Few residents with none/mild cognitive impairment had communication difficulties. For most conditions,

Table I Characteristics of Newly US Admitted Nursing Home Residents without Cancer by Cognitive Status, 2010 to 2016 $(n=8,613,080)$

\begin{tabular}{|c|c|c|c|}
\hline & \multicolumn{3}{|c|}{ Level of Cognitive Impairment } \\
\hline & Severe $(n=1,638,194)$ & Moderate $(n=I, 973,550)$ & None/Mild $(n=5,001,336)$ \\
\hline Age, years & Percentage & & \\
\hline $50-64$ & 6.4 & 8.8 & 17.7 \\
\hline $65-74$ & 11.8 & 15.4 & 25.5 \\
\hline $75-84$ & 31.9 & 32.6 & 31.7 \\
\hline $85+$ & 49.9 & 43.2 & 25.1 \\
\hline Women & 62.8 & 59.5 & 63.6 \\
\hline \multicolumn{4}{|l|}{ Race/Ethnicity } \\
\hline Non-Hispanic White & 78.7 & 81.2 & 83.9 \\
\hline Non-Hispanic Black & 12.4 & 10.9 & 9.8 \\
\hline Hispanic or Latino & 6.0 & 5.2 & 4.3 \\
\hline Other & 3.0 & 2.7 & 2.0 \\
\hline Married & 32.7 & 32.2 & 34.9 \\
\hline Rejects care & 14.3 & 9.1 & 3.6 \\
\hline \multicolumn{4}{|c|}{ Limitations in activities of daily living } \\
\hline Limited supervision & 9.6 & 14.4 & 21.9 \\
\hline Extensive & 56.4 & 62.3 & 63.3 \\
\hline Dependent & 33.9 & 23.3 & 14.8 \\
\hline Hospice & 4.1 & 1.8 & 0.6 \\
\hline \multicolumn{4}{|l|}{ Communication } \\
\hline Others understand & 71.1 & 90.7 & 99.6 \\
\hline Understands others & 68.9 & 90.4 & 99.6 \\
\hline \multicolumn{4}{|l|}{ Clinical conditions } \\
\hline Dementia/Alzheimer's & 62.9 & 34.7 & 7.5 \\
\hline Anxiety disorder & 19.8 & 18.6 & 18.1 \\
\hline Depression & 31.7 & 31.8 & 28.6 \\
\hline
\end{tabular}


Table 2 Potentially Painful Health Conditions of Newly Admitted US Nursing Home Residents without Cancer by Cognitive Status, 2010-2016 (n=8,613,080)

\begin{tabular}{|c|c|c|c|}
\hline \multirow[b]{2}{*}{ Painful Conditions } & \multicolumn{3}{|c|}{ Level of Cognitive Impairment } \\
\hline & Severe $(n=1,638,194)$ & Moderate $(n=I, 973,550)$ & None/Mild $(n=5,001,336)$ \\
\hline & \multicolumn{3}{|l|}{ Percentage } \\
\hline Heart Failure & 17.5 & 22.0 & 20.2 \\
\hline Coronary Artery Disease & 22.6 & 25.8 & 24.6 \\
\hline Venous Thromboembolism & 2.8 & 3.0 & 3.4 \\
\hline Peripheral Vascular/Arterial Disease & 5.8 & 7.2 & 7.6 \\
\hline Inflammatory Bowel Disease/Ulcerative Colitis & 0.7 & 0.9 & 1.2 \\
\hline Skin problems & 31.8 & 34.9 & 49.5 \\
\hline Arthritis & 21.3 & 23.7 & 30.1 \\
\hline Osteoporosis & 11.5 & 11.0 & 10.2 \\
\hline Fracture (hip and other) & 15.4 & 17.1 & 18.8 \\
\hline $\begin{array}{l}\text { Urinary Tract Infection } \\
\text { (last } 30 \text { days) }\end{array}$ & 18.2 & 16.2 & 11.5 \\
\hline
\end{tabular}

the percentage of residents diagnosed with potentially painful conditions was lowest in those with severe cognitive impairment (Table 2).

The percentage of residents with documentation of "any pain" based on self-assessment was $32.9 \%$ for those with severe cognitive impairment, $49.8 \%$ for those with moderate and $68.9 \%$ in those with no/mild cognitive impairment (Table 3). The percentage of residents with severe cognitive impairment receiving any pharmacologic treatment was $51.3 \%, 62.3 \%$ among those with moderate, and $76.9 \%$ among those with none/mild cognitive impairment. Among those with severe cognitive impairment, $24.4 \%$ had staff-assessment of pain. One in ten residents with moderate cognitive impairment and $4.8 \%$ of residents with no/mild cognitive impairment had staff-assessment of pain. Among residents with severe cognitive impairment, staff assessed "any pain" was documented among 37.2\% of residents, whereas $41.5 \%$ of those with moderate, and $50.6 \%$ of those with none/mild cognitive impairment had staff-assessed documentation of "any pain".

Table 4 shows that adjustment for sociodemographic factors, clinical, and potentially painful conditions did not explain the differences by level of cognitive impairment. For those with self-reported pain, residents with severe cognitive impairment (aPR: 0.68) and moderate cognitive impairment (aPR: 0.87) were less likely to have any pain documented relative to those with no/mild cognitive impairment. For those with staff-assessed pain, residents with severe cognitive impairment (aPR: 0.93) and moderate cognitive impairment (aPR: 0.97) were less likely to have any pain documented relative to those with no/mild cognitive impairment.

Figure 1 shows the frequency and severity of pain among those with self-reported pain. Almost constant pain was reported by $11.0 \%$ of those intact or with mild cognitive impairment, $9.9 \%$ of those with moderate cognitive impairment, and $7.4 \%$ of those with severe cognitive impairment (Figure 1A). The percentage of residents who reported that their pain was "Horrible" was $6.7 \%$ among those who were intact/with mild cognitive impairment, $6.0 \%$ among those with moderate cognitive impairment, and $4.6 \%$ among those with severe cognitive impairment (Figure 1B). Among residents with staff-assessed pain, $38.8 \%$ of those with none/mild cognitive impairment, $30.8 \%$ of those with moderate cognitive impairment, and $21.9 \%$ of those with severe cognitive impairment had daily pain documented (Figure 2).

Receipt of any pharmacologic treatment decreased by level of cognitive impairment. Except for the use of a scheduled pain treatment regimen, the percentage of residents treated with other pain management modalities (eg, any non-pharmacological pain management) decreased 
Table 3 Pain and Pain Management (5-Day Look-Back Period) Among Newly Admitted US Nursing Home Residents without Cancer by Level of Cognitive Impairment for All Residents and by Self- and Staff-Assessment, 2010 to 2016

\begin{tabular}{|l|l|l|l|}
\hline \multirow{2}{*}{} & \multicolumn{2}{l|}{ Level of Cognitive Impairment } \\
\cline { 2 - 4 } & Severe & Moderate & None/Mild \\
\hline Pain self-assessment (n=7,848, 108) & $\mathbf{n = 1 , 2 3 8 , 6 2 1}$ & $\mathbf{n = 1 , 7 7 7 , 4 9 5}$ & $\mathbf{n = 4 , 8 3 1 , 9 9 2}$ \\
Any pain & 32.9 & 49.8 & 68.9 \\
Any non-pharmacological pain management & 21.3 & 27.4 & 37.5 \\
Any pharmacologic pain management & 51.3 & 62.3 & 76.9 \\
Pro Re Nata (as needed) medication only & 28.8 & 35.8 & 43.4 \\
Scheduled pain regimen only & 10.5 & 9.0 & 6.9 \\
Pro Re Nata + Scheduled pain regimen & 12.0 & 17.4 & 26.6 \\
\hline Staff pain assessment (n=764,972) & $\mathbf{n = 3 9 9 , 5 7 3}$ & $\mathbf{n}=169,344$ \\
Any pain & 37.2 & $\mathbf{n = 1 9 6 , 0 5 5}$ & 50.6 \\
Any non-pharmacological pain management & 21.3 & 41.5 & 28.1 \\
Any pharmacologic pain management & 52.0 & 22.7 & 67.7 \\
Pro Re Nata medication only & 27.5 & 55.6 & 38.1 \\
Scheduled pain regimen only & 12.2 & 31.2 & 7.2 \\
Pro Re Nata + Scheduled pain regimen & 12.3 & 10.1 & 22.4 \\
\hline
\end{tabular}

Table 4 Association Between Level of Cognitive Impairment and Any Pain (5-Day Look-Back Period) Among Newly Admitted US Nursing Home Residents without Cancer, Prevalence Ratios

\begin{tabular}{|c|c|c|c|}
\hline & \multicolumn{3}{|c|}{ Level of Cognitive Impairment } \\
\hline & Severe & Moderate & None/Mild \\
\hline Pain self-assessment $(n=7,848,108)$ & $n=|, 238,62|$ & $n=I, 777,495$ & $n=4,83 I, 992$ \\
\hline$\%$ any pain & 32.9 & 49.8 & 68.9 \\
\hline Crude prevalence ratios & 0.50 & 0.74 & (reference) \\
\hline Partially adjusted prevalence ratios ${ }^{\mathrm{a}}$ & 0.65 & 0.84 & (reference) \\
\hline Fully adjusted prevalence ratios ${ }^{b}$ & 0.68 & 0.87 & (reference) \\
\hline Staff pain assessment $(n=764,972)$ & $n=399,573$ & $n=196,055$ & $n=169,344$ \\
\hline$\%$ any pain & 37.2 & 41.5 & 50.6 \\
\hline Crude prevalence ratios & 0.82 & 0.88 & (reference) \\
\hline Partially adjusted prevalence ratios ${ }^{a}$ & 0.88 & 0.93 & (reference) \\
\hline Fully adjusted prevalence ratios ${ }^{\mathrm{b}}$ & 0.93 & 0.97 & (reference) \\
\hline
\end{tabular}

Notes: ${ }^{a}$ Adjusted for sociodemographic and other baseline characteristics (see Table I) using robust Poisson models. ${ }^{b}$ Adjusted for sociodemographic and other baseline characteristics, health conditions, and potentially painful conditions (see Tables I and 2) using robust Poisson models.

with increasing levels of cognitive impairment for both selfreported, and staff-assessed pain (Table 3).

\section{Discussion}

We found the prevalence of pain (5-day look-back period) among newly admitted residents without cancer were lower in those with the most severe level of cognitive impairment relative to residents with no/mild cognitive deficits, consistent with previous reports. ${ }^{27}$ The differences in pain prevalence and use of pharmacological and non-pharmacological pain management across levels of cognitive impairment were observed in those able to self-report pain and among those with staff-assessed pain. Our working assumption is that cognitively impaired nursing home residents experience pain at a similar frequency as residents who are cognitively intact and most of the difference in reported pain and treatment of pain 
PANEL A: PAIN FREQUENCY

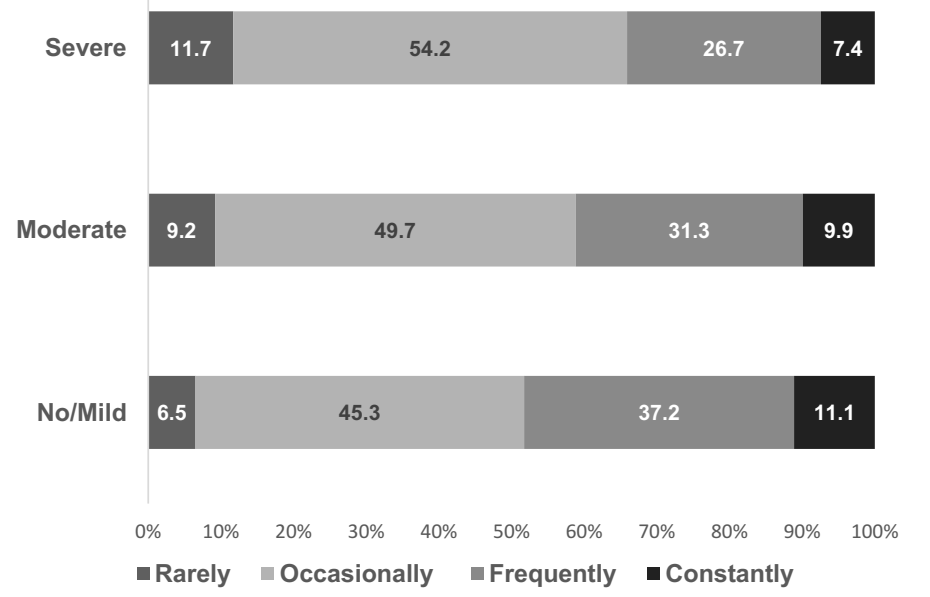

PANEL B: PAIN SEVERITY

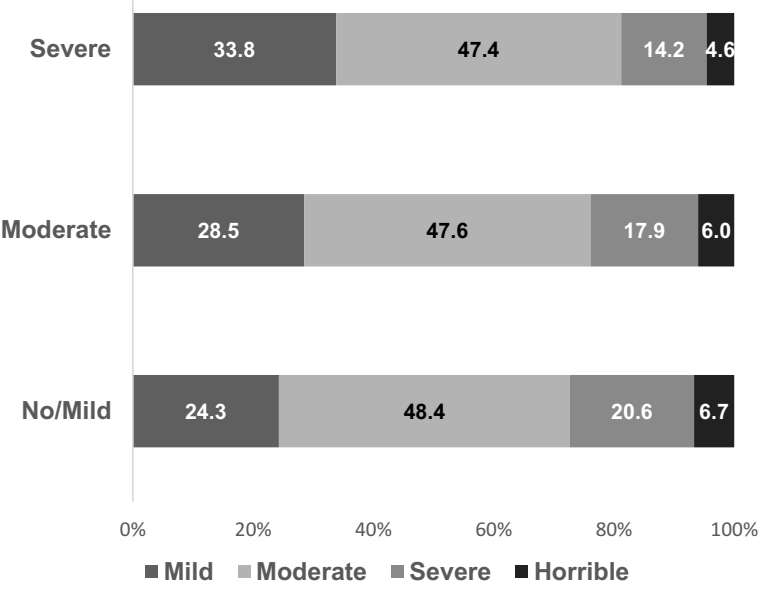

Figure I Pain frequency and severity (5-day look-back period) among newly admitted nursing home residents without cancer and with self-reported pain, stratified by cognitive impairment $(n=4,622,404)$.

Severe

45.9

32.2

21.9

Moderat

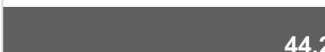

44.2

32.7

30.8

No/Mild

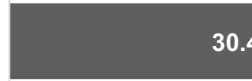

30.4

30.8

38.8

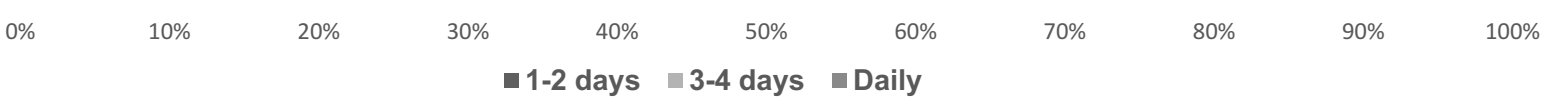

Figure 2 Pain frequency (5-day look-back period) by severity of cognitive impairment among newly admitted nursing home residents without cancer and with staff-assessed pain $(n=3 \mid 5,620)$.

between these groups is due to flaws in identification and assessment. It is unlikely that nociception is dampened by brain pathology in dementia. ${ }^{28}$

The MDS 3.0 manual stresses the importance of pain self-report, stating:

Obtaining information about pain directly from the resident, sometimes called 'hearing the resident's voice,' is more reliable and accurate than observation alone for identifying pain. $^{17}$

Yet, the capacity to self-report pain diminishes as the severity of cognitive impairment increases. ${ }^{29-31}$ We found that over three quarters of residents with severe cognitive impairment were administered a self-report instrument to assess their pain experience over the past 5 days, similar to what has been reported among nursing home residents with cancer. ${ }^{15}$ Severe cognitive impairment can result in disorientation in time and time distortion. ${ }^{12,13}$ Time distortions may be particularly concerning, manifesting in an inability to perceive the passage of time or accurately engage in retrospective timing, ${ }^{32}$ and the deterioration of short-term memory may result in complete loss of recent memories ${ }^{33}$ limiting assessments to only immediate recall. ${ }^{10}$ 
To characterize the extent of their pain, patients' verbal descriptions and ratings of pain have been suggested as the most reliable indicators. However, cognitive impairment is commonly associated with alterations in memory, language, speech, and consciousness which make recall and communication difficult and progressively worse in later stages of the disease. ${ }^{34}$ Impaired abstract thinking may also interfere with a resident's ability to understand the pain assessment task. ${ }^{10}$ Given these challenges, it is important to acknowledge the barriers and facilitators associated with the nursing home staff's ability to identify/assess pain. These include also lack of time, confidence, and knowledge. ${ }^{35,36}$ These are potentially modifiable factors that if addressed can make a difference to improve pain recognition in nursing homes.

Although the impact of dementia neuropathology on residents' perception of pain and pain processing may provide an explanation for differing rates of pain detection and treatment among residents at various levels of cognitive impairment (eg, higher pain tolerance in advanced Alzheimer's disease), scientific evidence in support of this argument is conflicting. ${ }^{34}$ In a Swedish study using the PAINAD (Pain Assessment in Advanced Dementia) scale, cognitively impaired residents had a higher incidence of pain $(56.2 \%$ vs $31 \%$ among intact residents). ${ }^{9}$ PAINAD assesses pain based on observations of breathing, vocalization, facial expression, body language, and consolability. ${ }^{37,38}$ Improvements to pain assessment among those with cognitive impairments are emerging. ${ }^{17}$ A combination of both observation and self-report for severely cognitively impaired individuals has been advised. ${ }^{39-41}$ This dual approach would retain the patient's voice while providing additional information and improving assessment accuracy.

Despite reported increases in use of opioids in some countries, ${ }^{42}$ in nursing homes pain treatment is inadequate among individuals with severe cognitive decline when compared to non-cognitively impaired individuals. Undetected pain or poorly assessed pain can lead to inadequately treated pain, which in older adults has been associated with several negative health outcomes including low quality of life, ${ }^{43,44}$ increased healthcare utilization and costs, ${ }^{45}$ and poor treatment outcomes. ${ }^{46} \mathrm{We}$ found that the prevalence of both nonpharmacological and pharmacological pain treatments was lower in residents with severe cognitive impairment relative to those with no/mild cognitive deficits, patterns that were similar in residents with self-reported and staff-assessed pain. Managing pain in nursing home residents is necessary to improve quality of life. Polypharmacy and physiological changes in old age may alter the pharmacokinetics and pharmacodynamics of medications. These aging-related changes may influence efficacy and side-effects of pain medications, and limit therapeutic options available for the management of pain in older adults. Pain can be persistent, with increasing severity associated with activity and functional limitations, ${ }^{47,48}$ underscoring the importance of improved recognition of pain and pain management in nursing home residents with cognitive impairment.

\section{Conclusions}

Using a 5-day look-back period, pain is common among newly admitted nursing home residents. Improved recognition of pain is warranted in residents with cognitive impairment. While the resident voice is important to include in the MDS assessment process, the MDS 3.0 pain assessment approach may result in under-recognition of pain. The under-recognition of pain may result in missed opportunities for pain management strategies to be employed. These data support revisiting the procedures for assessing pain among nursing home residents with cognitive impairment, with an eye towards providing safe, effective, compassionate care to those in life's final chapter.

\section{Statement of Ethics}

This study was conducted ethically in accordance with the World Medical Association Declaration of Helsinki. The study protocol was approved by the University of Massachusetts Medical School Institutional Review Board. The study used administrative data sources collected for purposes other than research, was granted a HIPAA waiver for research, and written informed consent was not required.

\section{Funding}

This research was funded by a grant from the National Institutes of Health (NR016977) to Dr. Lapane.

\section{Disclosure}

Deborah Sara Mack reports grants from the National Institutes of Health, during the conduct of the study. The authors have no other potential conflicts of interest to disclose for this work.

\section{References}

1. Won A, Lapane K, Gambassi G, Bernabei R, Mor V, Lipsitz LA. Correlates and management of nonmalignant pain in the nursing home. J Am Geriatr Soc. 1999;47(8):936-942. doi:10.1111/j.15325415.1999.tb01287.x

2. Boerlage AA, van Dijk M, Stronks DL, de Wit R, Rijt CCD. Pain prevalence and characteristics in three Dutch residential homes. Eur J Pain. 2008;12(7):910-916. doi:10.1016/j.ejpain.2007.12.014 
3. Hui D, Bruera E. A personalized approach to assessing and managing pain in patients with cancer. J Clin Oncol. 2014;32(16):1640-1646. doi:10.1200/JCO.2013.52.2508

4. Hoffmann F, van den Bussche $H$, Wiese B, Glaeske G, Kaduszkiewicz H. Diagnoses indicating pain and analgesic drug prescription in patients with dementia: a comparison to age- and sex-matched controls. BMC Geriatr. 2014;14(1):20. doi:10.1186/ 1471-2318-14-20

5. Bauer U, Pitzer S, Schreier MM, Osterbrink J, Alzner R, Iglseder B. Pain treatment for nursing home residents differs according to cognitive state - a cross-sectional study. BMC Geriatr. 2016;16(1):124. doi:10.1186/s12877-016-0295-1

6. Barry HE, Parsons C, Passmore AP, Hughes CM. Pain in care home residents with dementia: an exploration of frequency, prescribing and relatives' perspectives. Int J Geriatr Psych. 2015;30(1):55-63. doi:10.1002/gps.4111

7. AGS. Panel on Persistent Pain in Older Persons. Manage Persist Pain Older Persons. 2002;50(6):S205-S224.

8. Knopp-Sihota JA, Dirk KL, Rachor GS. Factors associated with pain assessment for nursing home residents: A systematic review and meta-synthesis. J Am Med Dir Assoc. 2019;20(7):884-892.e3. doi:10.1016/j.jamda.2019.01.156

9. Björk S, Juthberg C, Lindkvist M, et al. Exploring the prevalence and variance of cognitive impairment, pain, neuropsychiatric symptoms and ADL dependency among persons living in nursing homes; a cross-sectional study. BMC Geriatr. 2016;16(1):154. doi:10.1186/ s12877-016-0328-9

10. Zwakhalen SM, Hamers JP, Abu-Saad HH, Berger MP. Pain in elderly people with severe dementia: a systematic review of behavioural pain assessment tools. BMC Geriatr. 2006;6(1):3. doi:10.1186/1471-2318-6-3

11. World Health Organization. International Statistical Classification of Diseases and Related Health Problems 10th Revision (ICD-10) WHO Version for; 2016 Chapter V Mental and behavioural disorders (F00-F99) Organic, including symptomatic, mental disorders (F00-F09). 2016. http://apps.who.int/classifications/icd10/browse/ 2016/en\#/F00-F09. Accessed August 27, 2020.

12. Grewal RP. Awareness of time in dementia of the Alzheimer type. Psychol Rep. 1995;76(3 Pt 1):717-718. doi:10.2466/ pr0.1995.76.3.717

13. El Haj M, Kapogiannis D. Time distortions in Alzheimer's disease: a systematic review and theoretical integration. Aging Mech Dis. 2016;2(1):16016. doi:10.1038/npjamd.2016.16

14. Zwakhalen SMG, Koopmans RTCM, Geels PJEM, Berger MPF, Hamers JPH. The prevalence of pain in nursing home residents with dementia measured using an observational pain scale. Eur J Pain. 2009;13(1):89-93. doi:10.1016/j.ejpain.2008.02.009

15. Dubé CE, Mack DS, Hunnicutt JN, Lapane KL. Cognitive impairment and pain among nursing home residents with cancer. $J$ Pain Symptom Manage. 2018;55(6):1509-1518. doi:10.1016/j. jpainsymman.2018.02.012

16. Centers for Medicare and Medicaid Services. Long Term Care Minimum Data Set (MDS) 3.0. 2011 Available from: https://www. resdac.org/cms-data/request/cms-data-request-center.

17. Centers for Medicare and Medicaid Services. Long-Term Care Facility Resident Assessment Instrument 3.0 User's Manual, Version 1.14. 2016; Available from: https://downloads.cms.gov/files/ MDS-30-RAI-Manual-V114-October-2016.pdf. Accessed August 27, 2020.

18. Saliba D, Jones M, Streim J, Ouslander J, Berlowitz D, Buchanan J. Overview of Significant Changes in the Minimum Data Set for Nursing Homes Version 3.0. J Am Med Dir Assoc. 2012;13 (7):595-601. doi:10.1016/j.jamda.2012.06.001

19. Thomas KS, Wysocki A, Intrator O, Mor V. Finding Gertrude: the resident's voice in MDS 3. 0. J Am Med Dir Assoc. 2014;15 (11):802-806. doi:10.1016/j.jamda.2014.01.012
20. Saliba D, Buchanan J. Making the investment count: revision of the Minimum Data Set for nursing homes, MDS 3. 0. J Am Med Dir Assoc. 2012;13(7):602-610. doi:10.1016/j.jamda.2012.06.002

21. Chodosh J, Edelen MO, Buchanan JL, et al. Nursing home assessment of cognitive impairment: development and testing of a brief instrument of mental status. $J$ Am Geriatr Soc. 2008;56 (11):2069-2075. doi:10.1111/j.1532-5415.2008.01944.x

22. Saliba D, Buchanan J, Edelen MO, et al. MDS 3. 0: brief interview for mental status. J Am Med Dir Assoc. 2012;13(7):611-617. doi:10.1016/j.jamda.2012.06.004

23. Morris JN, Fries BE, Mehr DR, et al. MDS cognitive performance scale. J Gerontol a Biol Sci Med Sci. 1994;49(4):M174-M182. doi:10.1093/geronj/49.4.M174

24. Paquay L, De Lepeleire J, Schoenmakers B, Ylieff M, Fontaine O, Buntinx F. Comparison of the diagnostic accuracy of the Cognitive Performance Scale (Minimum Data Set) and the Mini-Mental State Exam for the detection of cognitive impairment in nursing home residents. Int $J$ Geriatr Psychiatry. 2007;22(4):286-293. doi:10.1002/gps.1671

25. Morris JN, Fries BE, Morris SA. Scaling ADLs Within the MDS. $J$ Gerontol a Biol Sci Med Sci. 1999;54(11):M546-M553. doi:10.1093/gerona/54.11.M546

26. Zou GY, Donner A. Extension of the modified Poisson regression model to prospective studies with correlated binary data. Stat Methods Med Res. 2013;22(6):661-670. doi:10.1177/0962280211427759

27. Reynolds KS, Hanson LC, DeVellis RF, Henderson M, Steinhauser KE. Disparities in pain management between cognitively intact and cognitively impaired nursing home residents. J Pain Symptom Manage. 2008;5(4):388-396. doi:10.1016/j.jpainsymman. 2008.01.001

28. Achterberg W, Lautenbacher S, Husebo B, Erdal A, Herr K. Pain in dementia. Pain Rep. 2019;5(1):e803. doi:10.1097/PR9.000000 0000000803

29. McDermott JH, Nichols DR, Lovell ME. A case-control study examining inconsistencies in pain management following fractured neck of femur: an inferior analgesia for the cognitively impaired. Emerg Med J. 2013;31(e1):e2-8. doi:10.1136/emermed-2013-203007

30. Markey G, Rabbani W, Kelly P. 022: association of dementia with delayed ED analgesia in patients over 70 with acute musculoskeletal injury. Emerg Med J. 2013;30(10):875. doi:10.1136/emermed-2013203113.22

31. Hadjistavropoulos T, Herr K, Prkachin KM, et al. Pain assessment in elderly adults with dementia. Lancet Neurol. 2014;13 (12):1216-1227. doi:10.1016/S1474-4422(14)70103-6

32. CDC. Cognitive impairment: a call for action now. February 2011. Available online at: https://www.cdc.gov/aging/pdf/cognitive_impair ment/cogimp_poilicy_final.pdf. Accessed August 27, 2020.

33. Alzheimer's Society. Symptoms and memory in the later stages of dementia. Available online at: https://www.alzheimers.org.uk/aboutdementia/symptoms-and-diagnosis/how-dementia-progresses/symp toms-memory. Accessed August 27, 2020.

34. Kunz M, Mylius V, Scharmann S, Schepelman K, Lautenbacher S. Influence of dementia on multiple components of pain. Eur J Pain. 2009;13(3):317-325. doi:10.1016/j.ejpain.2008.05.001

35. Zwakhalen S, Docking RE, Gnass I, et al. Pain in older adults with dementia: A survey across Europe on current practices, use of assessment tools, guidelines and policies. Schmerz bei älteren Menschen mit Demenz: eine Umfrage in Europa zu aktueller Praxis, Verwendung von Assessment-Instrumenten, Leitlinien und Handlungsanweisungen. Schmerz. 2018;32(5):364-373.

36. McAuliffe L, Nay R, O’Donnell M, Fetherstonhaugh D. Pain assessment in older people with dementia: literature review. $J$ Adv Nursing. 2008;65(1):210.

37. Achterberg WP, Pieper MJ, van Dalen-kok AH, et al. Pain management in patients with dementia. Clin Interv Aging. 2013;8:1471-1482. doi:10.2147/CIA.S36739 
38. Warden V, Hurley AC, Volicer V. Development and psychometric evaluation of the Pain Assessment in Advanced Dementia (PAINAD) Scale. J Am Med Dir Assoc. 2003;4(1):9-15. doi:10.1097/01. JAM.0000043422.31640.F7

39. Geriatricpain.org. Pain Assessment IN Advanced DementiaPAINAD Tool. Available online at: https://geriatricpain.org/assess ment/cognitively-impaired/painad/pain-assessment-advanceddementia-painad-tool. Accessed August 27, 2020.

40. Schofield P. The Assessment of Pain in Older People: UK National Guidelines. Age Ageing. 2018;47:1-22.

41. Herr K, Coyne PJ, Key T, et al. Pain assessment in the nonverbal patient: position statement with clinical practice recommendations. Pain Manag Nurs. 2006;7(2):44-52. doi:10.1016/j.pmn.2006.02.003

42. Muller AE, Clausen T, Sjøgren P, Odsbu I, Skurtveit S. Prescribed opioid analgesic use developments in three Nordic countries, 2006-2017. Scand J Pain. 2019;19(2):345-353. doi:10.1515/sjpain-2018-0307

43. Tsai PF, Beck C, Richards KC, Phillips L, Roberson PK, Evans J. The Pain Behaviors for Osteoarthritis Instrument for Cognitively Impaired Elders (PBOICIE). Res Gerontol Nurs. 2008;1 (2):116-122. doi:10.3928/19404921-20080401-07
44. Cavalieri TA. Management of pain in older adults. J Am Osteopath Assoc. 2005;105(3_suppl):12S-17S.

45. Cordner Z, Blass DM, Rabins PV, Black BS. Quality of life in nursing home residents with advanced dementia. J Am Geriatr Soc. 2010;58(12):2394-2400. doi:10.1111/j.1532-5415.2010.03170.x

46. Manchikanti L, Singh V, Datta S, Cohen SP, Hirsch JA. Comprehensive review of epidemiology, scope, and impact of spinal pain. Pain Physician. 2009;12(4):E35-E70.

47. Kolanowski A, Mogle J, Fick DM, et al. Pain, delirium, and physical function in skilled nursing home patients with dementia. J Am Med Dir Assoc. 2015;16(1):37-40. doi:10.1016/j.jamda.2014.07.002

48. Ahn H, Horgas A. The relationship between pain and disruptive behaviors in nursing home residents with dementia. BMC Geriatr. 2013;13(1):14. doi:10.1186/1471-2318-13-14

\section{Publish your work in this journal}

The Journal of Pain Research is an international, peer reviewed, open access, online journal that welcomes laboratory and clinical findings in the fields of pain research and the prevention and management of pain. Original research, reviews, symposium reports, hypothesis formation and commentaries are all considered for publication. The manuscript management system is completely online and includes a very quick and fair peer-review system, which is all easy to use. Visit http:// www.dovepress.com/testimonials.php to read real quotes from published authors. 